\title{
Huaier aqueous extract inhibits proliferation and metastasis of tuberous sclerosis complex cell models through downregulation of JAK2/STAT3 and MAPK signaling pathways
}

\author{
AILIN YANG $^{1,2}$, HAITAO FAN $^{3}$, YUNFANG ZHAO $^{1}$, XIAOJUN ZHA $^{4}$, \\ HONGBING ZHANG ${ }^{5}$, ZHONGDONG HU ${ }^{1}$ and PENGFEI TU ${ }^{1}$
}

\begin{abstract}
${ }^{1}$ Modern Research Center for Traditional Chinese Medicine, Beijing University of Chinese Medicine, Beijing 100029; ${ }^{2}$ School of Chinese Materia Medica, Beijing University of Chinese Medicine, Beijing 100102; ${ }^{3}$ College of Bioengineering, Beijing Polytechnic, Beijing 100029; ${ }^{4}$ Department of Biochemistry and Molecular Biology, School of Basic Medicine, Anhui Medical University, Hefei, Anhui 230032; ${ }^{5}$ State Key Laboratory of Medical Molecular Biology, Department of Physiology, Institute of Basic Medical Sciences, Chinese Academy of Medical Sciences and School of Basic Medicine,
\end{abstract}

Peking Union Medical College, Beijing 100005, P.R. China

Received March 10, 2016; Accepted July 18, 2016

DOI: $10.3892 / o r .2016 .4969$

\begin{abstract}
Tuberous sclerosis complex (TSC) is a genetic disorder with formation of benign tumors in many different organs. It has attracted increasing attention from researchers to search for therapeutic drugs for TSC patients. Traditional Chinese medicine (TCM) has become an important source for finding antitumor drugs. Trametes robiniophila Murr. (Huaier) is a kind of officinal fungi in China and has been applied in TCM for approximately 1,600 years. A large number of clinical applications have revealed that Huaier has good antitumor effect. In this study, we have investigated the effects of Huaier aqueous extract on two TSC cell models, including inhibition of proliferation, induction of apoptosis, cell cycle arrest, and anti-metastasis. We demonstrated that Huaier aqueous extract inhibited JAK2/STAT3 and MAPK signaling pathways in a dose-dependent manner. Therefore, based on the low toxicity
\end{abstract}

Correspondence to: Dr Zhongdong Hu or Professor Pengfei Tu, Modern Research Center for Traditional Chinese Medicine, Beijing University of Chinese Medicine, 11 North Third Ring Road, Chaoyang District, Beijing 100029, P.R. China

E-mail: zdhu@bucm.edu.cn

E-mail: pengfeitu@163.com

Abbreviations: TSC, tuberous sclerosis complex; LAM, lymphangiomyomatosis; TCM, traditional Chinese medicine; TSC1, tuberous sclerosis 1; TSC2, tuberous sclerosis 2; mTOR, mechanistic target of rapamycin; PI3K, phosphatidylinositol 3-kinase; ERK, extracellular signal-regulated kinase; MAPK, mitogen-activated protein kinase; MEFs, mouse embryonic fibroblasts; STAT3, signal transducer and activator of transcription 3

Key words: Huaier, tuberous sclerosis complex, proliferation, metastasis, JAK2/signal transducer and activator of transcription 3, mitogen-activated protein kinase, traditional Chinese medicine and the multi-targets of Huaier treatment, Huaier may be a promising therapeutic drug for TSC.

\section{Introduction}

Tuberous sclerosis complex (TSC) is a genetic disease characterized by formation of benign tumors in multiple organ systems, including the brain, eyes, heart, kidneys, skin and lungs. There are several typical symptoms in TSC patients, including epilepsy, mental deterioration, facial angiofibroma, pulmonary lymphangiomyomatosis (LAM), kidney angiomyolipoma, and renal cyst. The incidence of TSC is approximately 1:6,000-10,000 (1-3).

Tuberous sclerosis 1 (TSC1) and 2 (TSC2) are two tumor suppressor genes located upstream of mechanistic target of rapamycin (mTOR) (4). TSC is caused by inactivating mutations of either TSC1 or TSC2. Hyperactivation of mTOR caused by deficiency of either TSC1 or TSC2 is thought to be the major cause of TSC development $(1,5,6)$. Therefore, mTOR inhibition is considered to be effective in the treatment of TSC patients. However, rapamycin (mTOR specific inhibitor) mediated disruption of the feedback suppression of phosphatidylinositol 3-kinase (PI3K)/AKT signaling and extracellular signal-regulated kinase (ERK)/mitogen-activated protein kinase (MAPK) signaling from mTOR limited the therapeutic effect of rapamycin on TSC patients (7-9). Moreover, the effect of rapamycin treatment is not very satisfactory because of the immunosuppressive property and drug dependence of rapamycin $(10,11)$. Thus, to ameliorate the treatment for TSC, it is extremely important to search for new therapeutic drugs for TSC.

Increasing attention has been paid to antitumor drugs originating from traditional Chinese medicine $(12,13)$. As a kind of officinal fungi, Trametes robiniophila Murr. (Huaier) is applied for the treatment of inflammation and cancer in China. There are increasing evidence reporting that Huaier exerts anti-neoplastic activities through inhibition of proliferation, induction of apoptosis, suppression of angiogenesis, and 
inhibition of metastasis of cancer cells (14-18). However, the underlying mechanisms of anticancer effect of Huaier remain poorly understood.

In this study, we investigated the effect of Huaier aqueous extract on Tsc1- or Tsc2-null mouse embryonic fibroblasts (MEFs), two widely used TSC cell models. Huaier aqueous extract inhibited the proliferation and metastasis, and promoted cell cycle arrest and apoptosis of $T s \mathrm{Cl}^{-/-}$or $T_{s c} 2^{-/}$MEFs. Interestingly, we have demonstrated that Huaier aqueous extract inhibited JAK2/signal transducer and activator of transcription 3 (STAT3) and MAPK signaling pathways in these two TSC cell models. Thus, this study provide new insight into the treatment of TSC.

\section{Materials and methods}

Reagents and antibodies. Dulbecco's modified Eagle's medium (DMEM), fetal bovine serum (FBS), and $0.25 \%$ trypsin-EDTA were purchased from Corning Life Sciences (Corning, NY, USA). Antibodies against JAK2, p-JAK2 (Y1007/1008), STAT3, p-STAT3 (Y705), ERK, p-ERK, c-Jun N-terminal kinase (JNK), p-JNK, N-cadherin, $\beta$-catenin, TCF8/ZEB1, claudin-1, Slug, Snail, and MMP9 were purchased from Cell Signaling Technology, Inc. (Danvers, MA, USA). Anti-MMP9 antibody was purchased from Abcam (Cambridge, UK). Anti- $\beta$-actin antibody was purchased from Abgent, Inc. (San Diego, CA, USA). Anti-mouse and rabbit IgG-HRP antibodies were from Santa Cruz Biotechnology, Inc. (Santa Cruz, CA, USA).

Preparation of Huaier aqueous extract. The electuary ointment of Huaier (Gaitianli Medicine Co., Ltd., Jiangsu, China) was dissolved in complete medium and then sterilized by filtration with a $0.22-\mathrm{mm}$ filter to get the $10 \mathrm{mg} / \mathrm{ml}$ stock solution, which was stored at $4^{\circ} \mathrm{C}$ for short-term storage.

Cell culture. $T s c 1^{-/-}$MEFs and $T s c 2^{-/-}$MEFs were previously described $(7,19)$. Cells were maintained in DMEM containing $10 \% \mathrm{FBS}$ and $1 \%$ penicillin/streptomycin in $5 \% \mathrm{CO}_{2}$ at $37^{\circ} \mathrm{C}$.

Cell proliferation assay. Tsc1 ${ }^{-/-} \mathrm{MEFs}$ and $T s c 2^{-/-} \mathrm{MEFs}$ were seeded in 96 -well plate at a density of $2.0 \times 10^{3}$ cells/well. Twenty-four hours later, cells were treated with Huaier aqueous extract at the indicated concentrations of ranging from 0 to $8 \mathrm{mg} / \mathrm{ml}$, and incubated for 12,24 and $48 \mathrm{~h}$, respectively. Ten microliters CCK-8 reagent (Dojindo, Kumamoto, Japan) was added to each well, and then incubated for $2 \mathrm{~h}$ at $37^{\circ} \mathrm{C}$. The optical density values were measured at $450 \mathrm{~nm}$ using a microplate reader (Perkin-Elmer, Waltham, MA, USA).

Colony formation. Tsc1 $1^{-/-}$MEFs and Tsc $2^{-/-}$MEFs were seeded in a 6-well plate at a density of 1,000 cells/well. Twenty-four hours later, cells were treated with Huaier aqueous extract at the indicated concentrations. After 10 days of treatment, the cells were fixed with methanol for $15 \mathrm{~min}$, and then colonies were stained with $0.1 \%$ crystal violet. The cell colonies were photographed using a digital camera (Leica Microsystems $\mathrm{GmbH}$, Wetzlar, Germany).

Hoechst staining. Cells were washed twice with PBS and fixed with $4 \%$ paraformaldehyde for $15 \mathrm{~min}$, and stained with
Hoechst 33258 (Biyuntian Biotechnology Co., Ltd., Shanghai, China) for $30 \mathrm{~min}$ in the dark before washed with PBS again. Then cells were observed under an inverted fluorescence microscope (Leica Microsystems GmbH).

Apoptosis analysis. Tsc1 $1^{-/-}$MEFs and $T s c 2^{-/-}$MEFs were seeded in 12 -well plates at $2.5 \times 10^{5}$ cells/well. The next day, the cells were treated with Huaier aqueous extract at 4 or $8 \mathrm{mg} / \mathrm{ml}$ for 48 h. Apoptosis was analyzed with an Annexin V-FITC apoptosis detection kit (BD Biosciences, Franklin Lakes, NJ, USA) according to the manufacturer's instructions. In brief, cells were collected and washed twice with PBS, then resuspended at a concentration of $1 \times 10^{6}$ cells $/ \mathrm{ml}$ in binding buffer. Five microliters Annexin V-FITC and $5 \mu \mathrm{l}$ propidium iodide (PI) were added and incubated for $15 \mathrm{~min}$ at room temperature in the dark. Finally, $400 \mu \mathrm{l}$ the binding buffer was added and then cells were analyzed using a flow cytometer (BD Biosciences).

Cell cycle analysis. Tsc1 $1^{-/-}$MEFs and Tsc $2^{-/-}$MEFs were seeded in 6-well plates at $5 \times 10^{5}$ cells/well. After 12 -h starvation in serum-free medium, cells were treated with Huaier aqueous extract at the concentrations of 0,4 and $8 \mathrm{mg} / \mathrm{ml}$ for $48 \mathrm{~h}$, and then cells were collected, washed twice with PBS and fixed overnight with $70 \%$ ethanol at $4^{\circ} \mathrm{C}$. The next day, the fixed cells were centrifuged at $1,000 \mathrm{x} \mathrm{g}$ for $5 \mathrm{~min}$ and washed twice with PBS, then cells were resuspended with $500 \mu \mathrm{l}$ binding buffer containing RNaseA and PI (Biyuntian Biotechnology Co., Ltd.). After $30-\mathrm{min}$ incubation at $37^{\circ} \mathrm{C}$ in the dark, the cells were analyzed by flow cytometry.

In vitro scratch assay. Cells were seeded in 12-well plates. The complete medium was replaced with serum-free medium when the cells grew to a subconfluent state. After 12-h starvation, a straight cell-free wound was created with a $10-\mu 1$ pipette tip and washed twice with PBS, then the cells were maintained in serum-free medium containing Huaier aqueous extract at the concentrations of 0,2 and $4 \mathrm{mg} / \mathrm{ml}$. The cells were observed and the scratch width was measured at 0,12 and $24 \mathrm{~h}$. The migration distances were analyzed quantitatively.

Cell invasion assay. Tsc1 $1^{-/-} \mathrm{MEFs}$ and $T s c 2^{-/-}$MEFs were maintained in serum-free medium for $12 \mathrm{~h}$ to reduce the interference of serum. Transwell chambers were placed in 24-well plates to constitute the Transwell system. The Matrigel (BD Biosciences, San Jose, CA, USA) was dissolved in serum-free medium at a ratio of $1: 12$, and then $60 \mu 1$ mixture was put to the upper chamber gently. Next the Transwell system was incubated at $37^{\circ} \mathrm{C}$ for $4 \mathrm{~h}$. The cells were collected and resuspended in serum-free medium containing different concentrations of Huaier aqueous extract. In brief, $1 \times 10^{5}$ cells suspended in $200 \mu \mathrm{l}$ serum-free medium containing drug were added to the upper chamber, and $750 \mu \mathrm{l}$ complete medium containing $10 \% \mathrm{FBS}$ was added to the lower chamber. After incubation for 12 or $24 \mathrm{~h}$, the cells on the upper surface of the membrane were wiped off with cotton swabs, and the cells on the lower surface of the membrane were fixed with ethanol for $15 \mathrm{~min}$, then stained with crystal violet for $10 \mathrm{~min}$ and washed twice with PBS. The successfully invaded cells were observed and photographed on 5 random fields with an inverted microscope. 

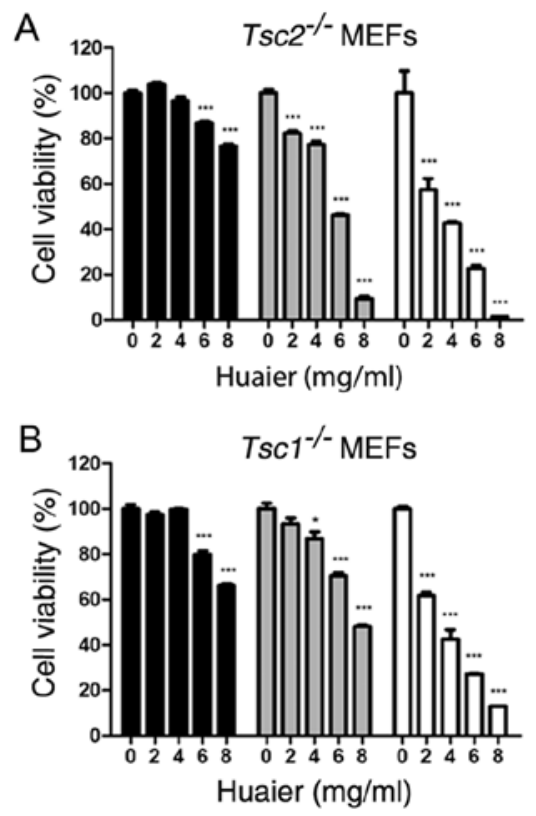

C

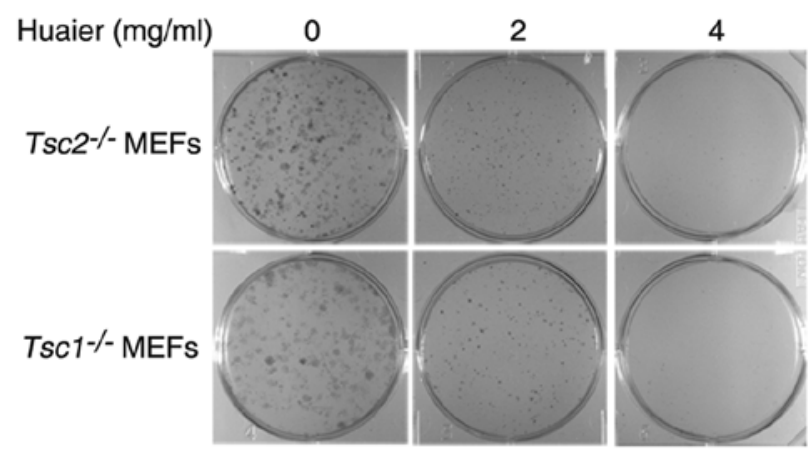

Figure 1. Huaier inhibits the proliferation of $T s c 1^{-/-}$or $T s c 2^{-/-}$mouse embryonic fibroblasts (MEFs). (A) $T s c 2^{-/}$MEFs and (B) $T s c 1^{-/-}$MEFs were treated with Huaier aqueous extract at the concentrations of $0,2,4,6$ and $8 \mathrm{mg} / \mathrm{ml}$ for 12,24 and $48 \mathrm{~h}$, respectively. Cell viability was measured by the CCK- 8 assay. ${ }^{*} \mathrm{P}<0.05,{ }^{* * *} \mathrm{P}<0.001$. (C) $T s c 2^{-/-}$MEFs and $T s c 1^{-/}$MEFs were treated with Huaier aqueous extract at the concentrations of 0,2 and $4 \mathrm{mg} / \mathrm{ml}$ for 10 days and then stained with crystal violet. Representative images are presented.
Western blotting. Cells were washed twice with PBS and harvested with cell lysis solution as previously described (20). The cell lysate was boiled at $98^{\circ} \mathrm{C}$ for $10 \mathrm{~min}$. The proteins were separated by $4-12 \%$ Bis-Tris Nu-PAGE (Invitrogen, Carlsbad, CA, USA) and then transferred onto PVDF membrane. The membrane was blocked with $3-5 \%$ skim milk in TBST at room temperature for $1 \mathrm{~h}$, and then incubated with the primary antibodies at $4{ }^{\circ} \mathrm{C}$ overnight, followed by the incubation with the HRP-conjugated secondary antibody at room temperature for 2 h. Finally, the membrane was washed three times in TBST and detected by chemiluminescence.

Statistical analysis. The data groups were compared with the two-tailed Student's t-test using GraphPad Prism 5.0 software. The data are presented as mean \pm SD. $\mathrm{P}<0.05$ was considered to be statistically significant.

\section{Results}

Huaier inhibits proliferation of $T s c 1^{-/-}$or Tsc2 $2^{-/-}$MEFs. To evaluate the effect of Huaier aqueous extract on $T s c 1^{-/-}$or $T s c 2^{-/}$MEFs, we examined cell viability with the CCK-8 assay. $T s c 1^{-/-}$or $T s c 2^{-/-}$MEFs were treated with Huaier at the indicated concentrations $(0,2,4,6$ and $8 \mathrm{mg} / \mathrm{ml})$ for 12 , 24 and 48 h, respectively. As shown in Fig. 1A and B, Huaier significantly suppressed the proliferation of $T s c 2^{-/}$or $T s c 1^{-1}$ MEFs in a time- and dose-dependent manner. The IC50 values of $T s c 1^{-/-}$or $T s c 2^{-/-}$MEFs exposed to Huaier aqueous extract of various concentrations for $48 \mathrm{~h}$ were 3.89 and $3.56 \mathrm{mg} / \mathrm{ml}$, respectively. Furthermore, we performed colony formation assay to assess the effect of Huaier aqueous extract on cell proliferation. Result indicated that $\mathrm{Tscl}^{-/-}$or $T s c 2^{-/-} \mathrm{MEFs}$ treated with Huaier aqueous extract formed smaller and fewer colonies in a dose-dependent manner (Fig. 1C).

Huaier induced cell cycle arrest of $T s c 1^{-/-}$or $T s c 2^{-/-}$MEFs. To investigate whether the inhibitory effect of Huaier aqueous extract was attributed to cell cycle arrest, we performed flow cytometry assay to evaluate cell cycle distribution of $T s \mathrm{Cl}^{-/-}$or $T s c 2^{-/-}$MEFs exposed to Huaier. $T s c 1^{-/-}$or $T s c 2^{-/-}$MEFs were treated with Huaier aqueous extract for $48 \mathrm{~h}$. As shown in Fig. 2A, $T s c 2^{-/-}$MEFs exposed to Huaier showed significantly decreased fraction of the G0/G1 phase and increased fraction of the $\mathrm{S}$ phase in a dose-dependent manner. In addition, $\mathrm{TsCl}^{-/}$ MEFs treated with Huaier exhibited significantly decreased fraction of the G2/M phase and increased fraction of the $\mathrm{S}$ phase (Fig. 2B). Taken together, these results revealed that Huaier-induced S-phase arrest was partially responsible for the proliferation inhibition of $T s c 1^{-/-}$or $T s c 2^{-/-}$MEFs.

Huaier induces apoptosis in $\mathrm{Tscl}^{-/-}$or $\mathrm{Tsc}_{\mathrm{s}} \mathrm{F}^{-/} \mathrm{MEFs}$. Next we performed Hoechst staining assay to determine the effect of Huaier aqueous extract on apoptosis. Apoptotic cells could be stained with Hoechst 33258 dye. As observed in Fig. 3A, the nuclei in the untreated $T s c 1^{-/}$or $T s c 2^{-/-}$MEFs were stained with a less bright blue fluorescence and these two cells appeared to be intact oval shape. Whereas, more condensed or fragmented chromatin were observed in $\mathrm{Tscl}^{-/-}$or $\mathrm{Tsc}_{\mathrm{s}} 2^{-/-}$MEFs exposed to Huaier aqueous extract. To further explore the effect of Huaier on apoptosis in $T s c 1^{-/-}$or $T s c 2^{-/-}$MEFs, we conducted flow cytometry analysis with Annexin V-FITC/PI staining. As shown in Fig. 3B, the apoptosis rate of $T s c 1^{-/-}$or $T s c 2^{-/-}$MEFs increased in a dose-dependent manner in response to Huaier. Collectively, Huaier aqueous extract promotes apoptosis of $T s c 1^{-/-}$or $T s c 2^{-/-}$MEFs.

Effect of Huaier treatment on the morphology of Tsc1/- or $T s c 2^{-/} M E F s$. Next we determined the effect of Huaier aqueous extract on cell morphology. $T s c 1^{-/-}$or $T s c 2^{-/-} \mathrm{MEFs}$ were treated with Huaier aqueous extract at a concentration of 4 or $8 \mathrm{mg} / \mathrm{ml}$ for $24 \mathrm{~h}$. As shown in Fig. 4, the untreated cells showed plump cell body, homogeneous cytoplasm, and good refraction. However, Huaier treatment led to shrinked cell body and weakened refraction. Moreover, more cells became round and died, which was concomitant with an increase in the concentration of Huaier. 
A
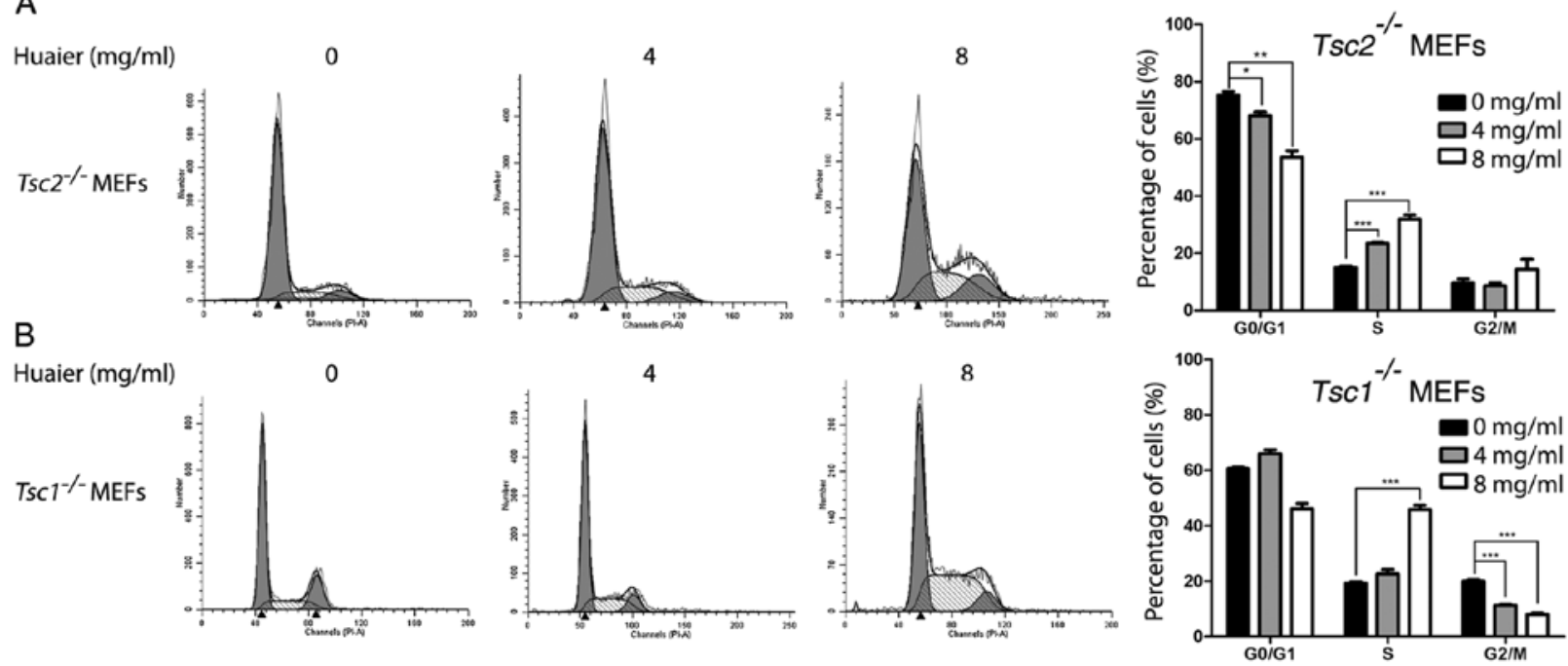

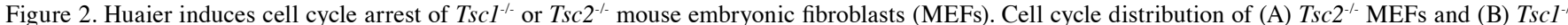
MEFs treated with Huaier aqueous extract at the concentrations of 0,4 and $8 \mathrm{mg} / \mathrm{ml}$ for 48 h were examined by flow cytometry. ${ }^{*} \mathrm{P}<0.05,{ }^{* * *} \mathrm{P}<0.01,{ }^{* * * *} \mathrm{P}<0.001$.

A

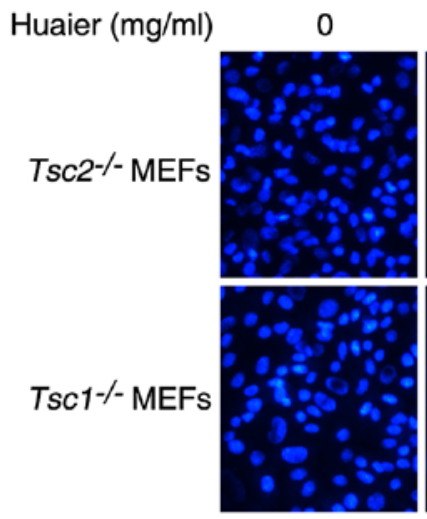

4
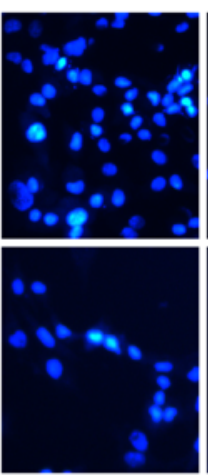

8

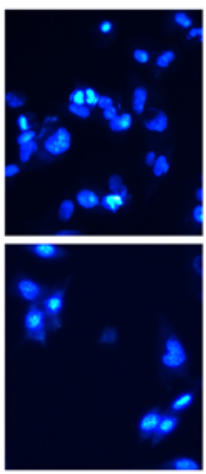

B
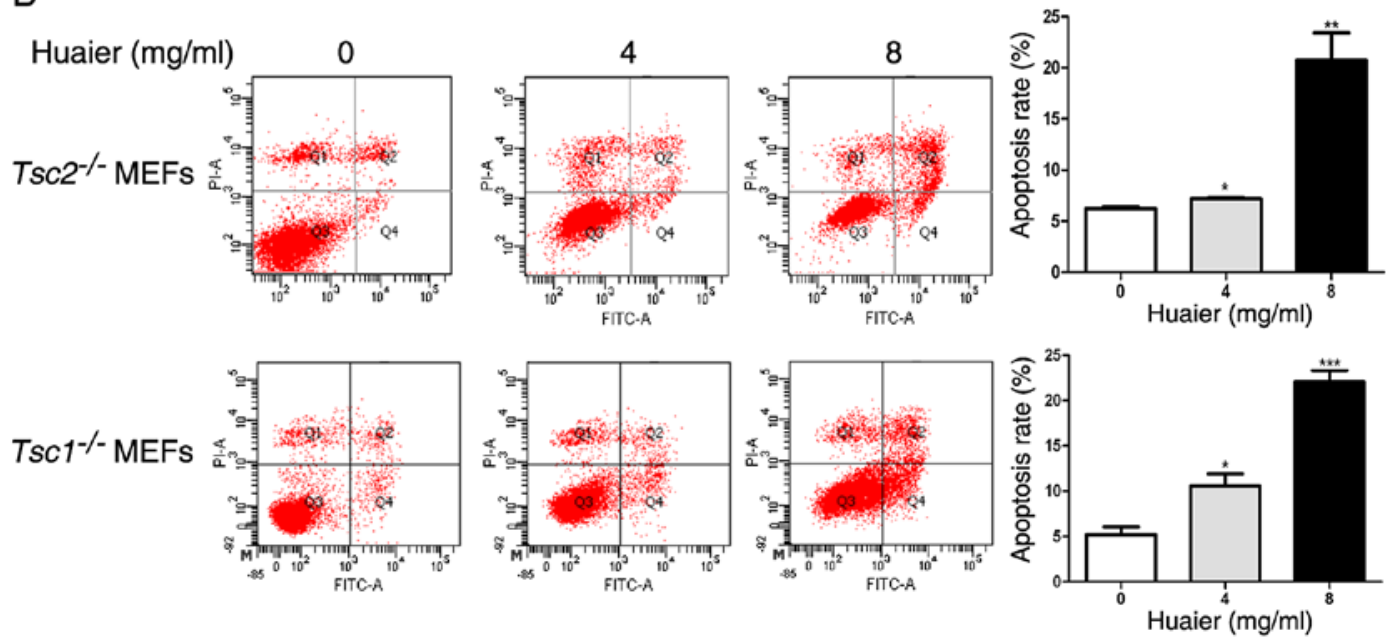

Figure 3. Huaier induces apoptosis in $T s c 1^{-\%}$ or $T s c 2^{--}$mouse embryonic fibroblasts (MEFs). (A) $T s c 2^{-/}$MEFs and $T s c 1^{-/}$MEFs treated with Huaier aqueous extract at the concentrations of 0,4 and $8 \mathrm{mg} / \mathrm{ml}$ for $48 \mathrm{~h}$ were stained with Hoechst 33258 and were photographed under a fluorescence microscope. Representative images are presented (x200). (B) $T s c 2^{-/}$MEFs and $T s c 1^{-1-}$ MEFs treated with Huaier aqueous extract at the concentrations of $0,4 \mathrm{and} 8 \mathrm{mg} / \mathrm{ml}$ for $48 \mathrm{~h}$ were subjected to analysis of apoptosis by flow cytometry. ${ }^{*} \mathrm{P}<0.05,{ }^{* *} \mathrm{P}<0.01,{ }^{* * *} \mathrm{P}<0.001$.

Huaier inhibits cell motility of Tsc $1^{-\leftarrow}$ or $T_{s c} 2^{--}$MEFs. Migration and invasion play a critical role in metastasis of cancer cells (21). To evaluate the migration ability of cells in vitro, we performed in vitro scratch assay. We treated $T s c 1^{-/}$or $T s c 2^{-/}$MEFs with
Huaier aqueous extract at the concentrations of 0,2 and $4 \mathrm{mg} /$ $\mathrm{ml}$, and then measured the scratch width at time-points of 0 , 12 and 24 h. As shown in Fig. 5A, the migration distance was decreased in response to Huaier in a dose-dependent manner. 


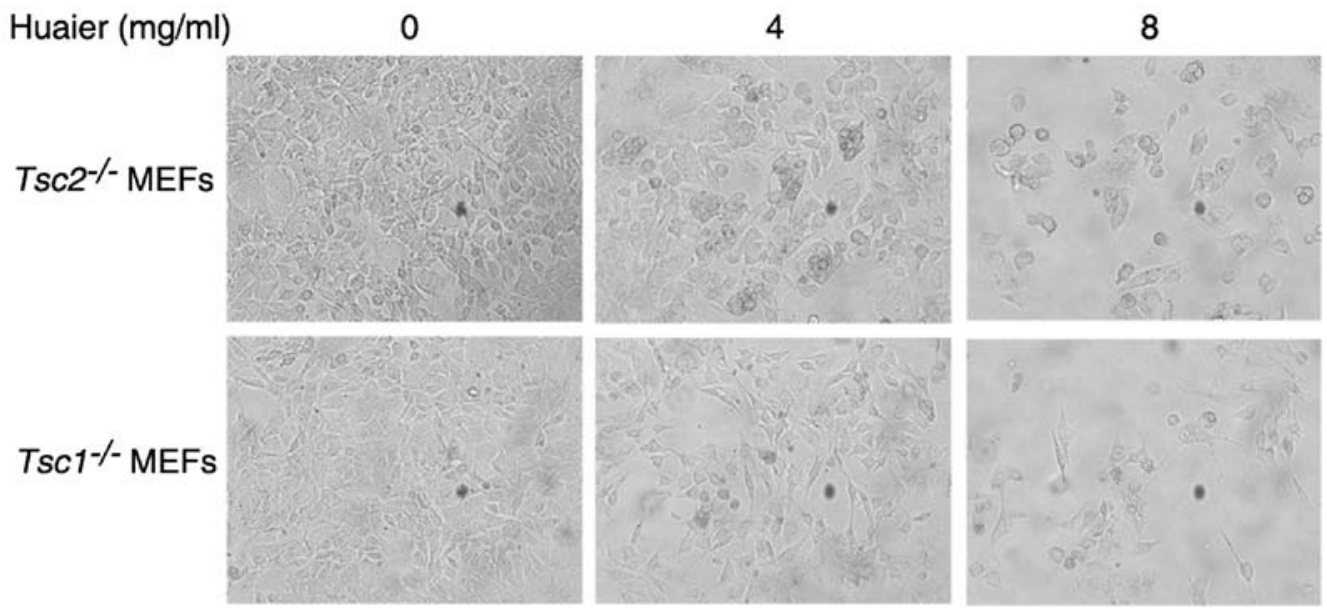

Figure 4. Effect of Huaier treatment on the morphology of $T s c 1^{-}$or $T s c 2^{-\%}$ mouse embryonic fibroblasts (MEFs). The morphology of $T s c 2^{-/}$MEFs and $T s c 1^{-1}$ MEFs treated with Huaier aqueous extract at the concentrations of 0,4 and $8 \mathrm{mg} / \mathrm{ml}$ for $48 \mathrm{~h}$ were observed. Representative images are presented (x200).
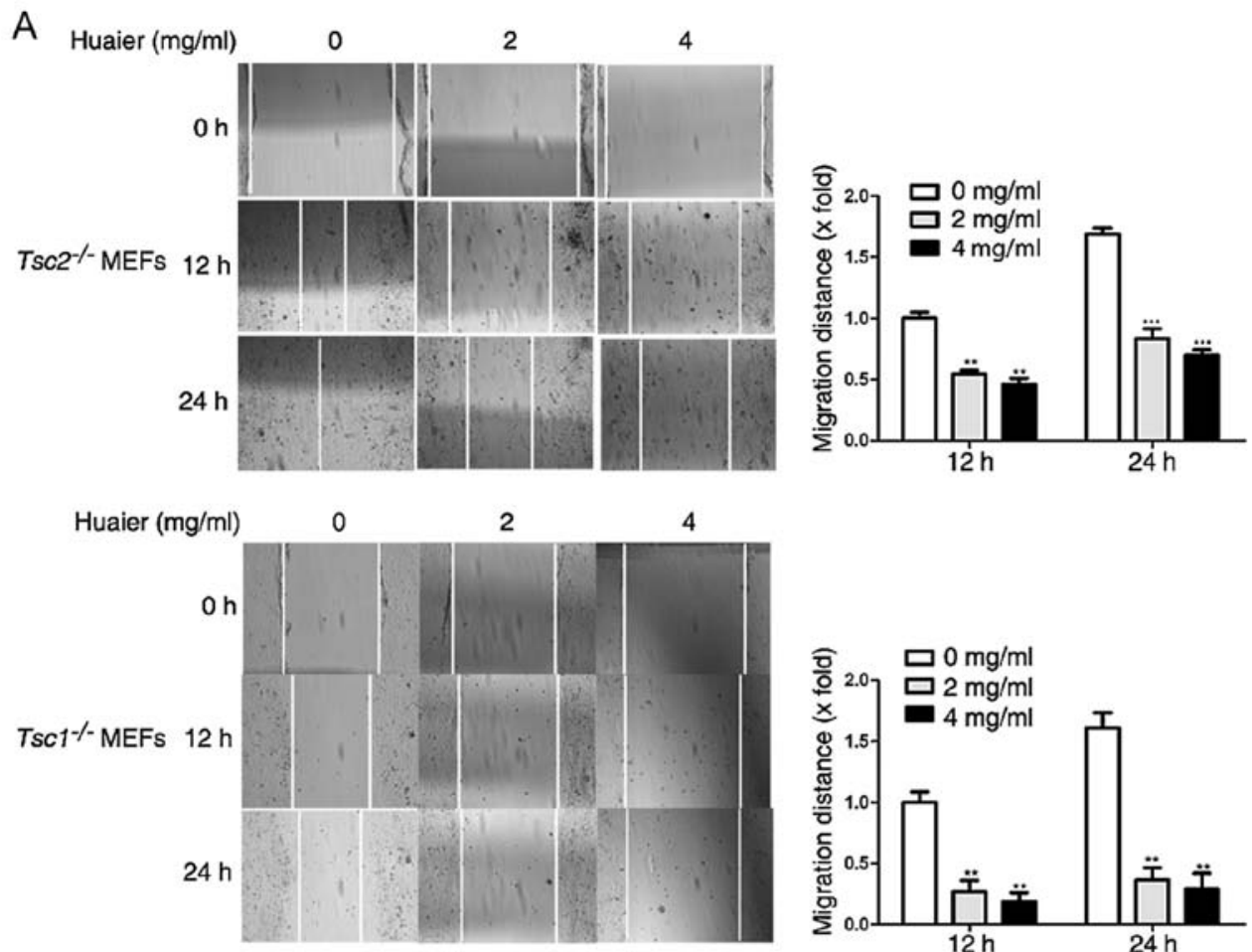

B
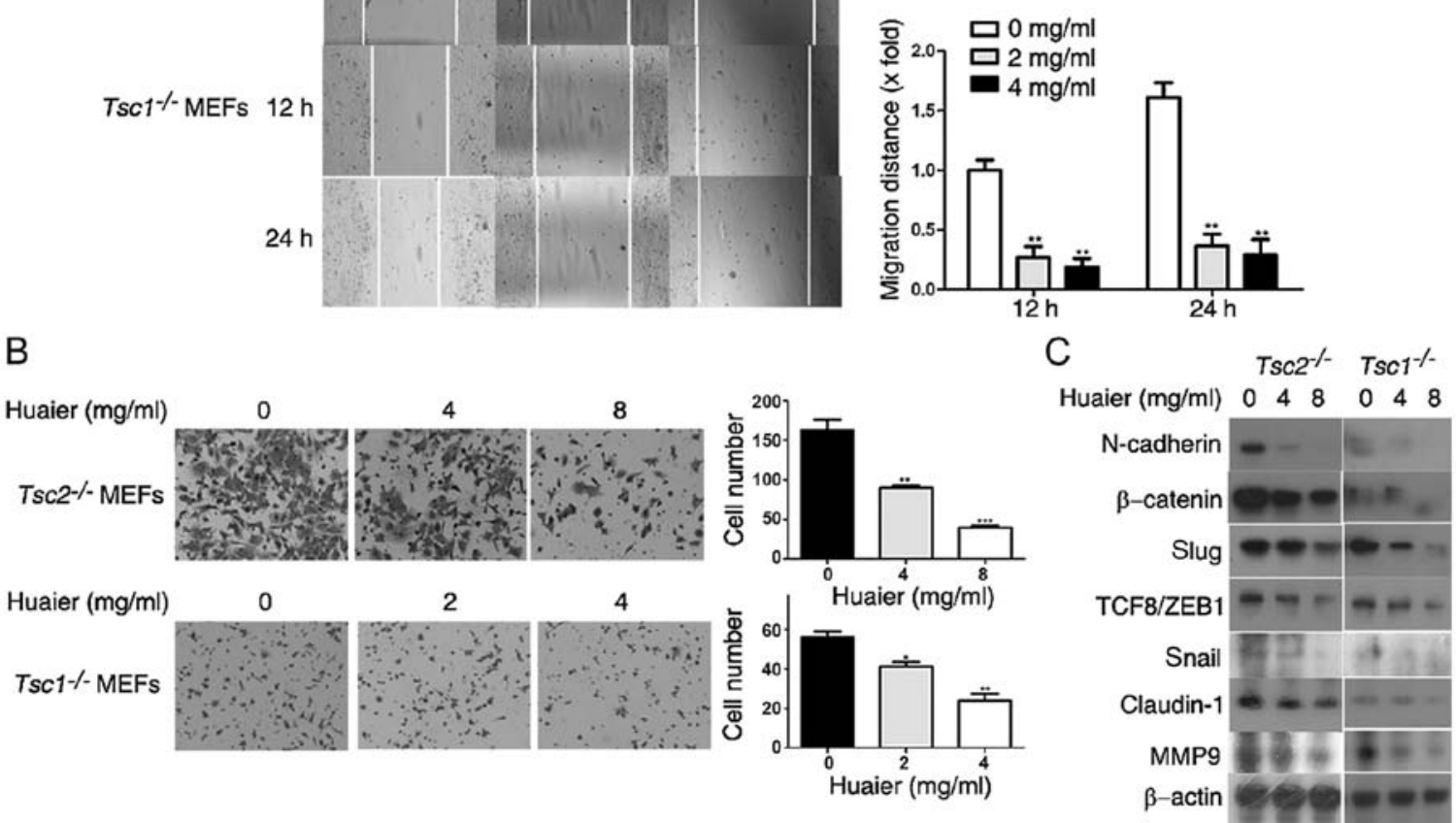

Figure 5. Huaier inhibits cell motility of $T s c 1^{-\digamma}$ or $T s c 2^{-/}$mouse embryonic fibroblasts (MEFs). (A) $T s c 2^{-\digamma}$ MEFs and $T s c 1^{-\digamma}$ MEFs treated with Huaier aqueous extract at the concentrations of 0,2 and $4 \mathrm{mg} / \mathrm{ml}$ were subjected to in vitro scratch assay and observed at 0,12 and $24 \mathrm{~h}$, respectively. Left panel, representative images (x 100); right panel, quantitative data. ${ }^{* *} \mathrm{P}<0.01,{ }^{* * * *} \mathrm{P}<0.001$. (B) $T s c 2^{-/}$MEFs or $T s c 1^{-/}$MEFs treated with Huaier aqueous extract at the concentrations of 0,4 and 8 or 0,2 and $4 \mathrm{mg} / \mathrm{ml}$ for 12 or $24 \mathrm{~h}$, respectively, were subjected to cell invasion assay. Representative images are presented (x200). (C) Tsc2 $2^{-/} \mathrm{MEFs}$ and $T s c 1^{-/-}$MEFs treated with Huaier aqueous extract at the concentrations of 0,4 and $8 \mathrm{mg} / \mathrm{ml}$ for $48 \mathrm{~h}$ were subjected to immunoblotting. ${ }^{*} \mathrm{P}<0.05,{ }^{* * *} \mathrm{P}<0.01$, ${ }^{* * *} \mathrm{P}<0.001$ 

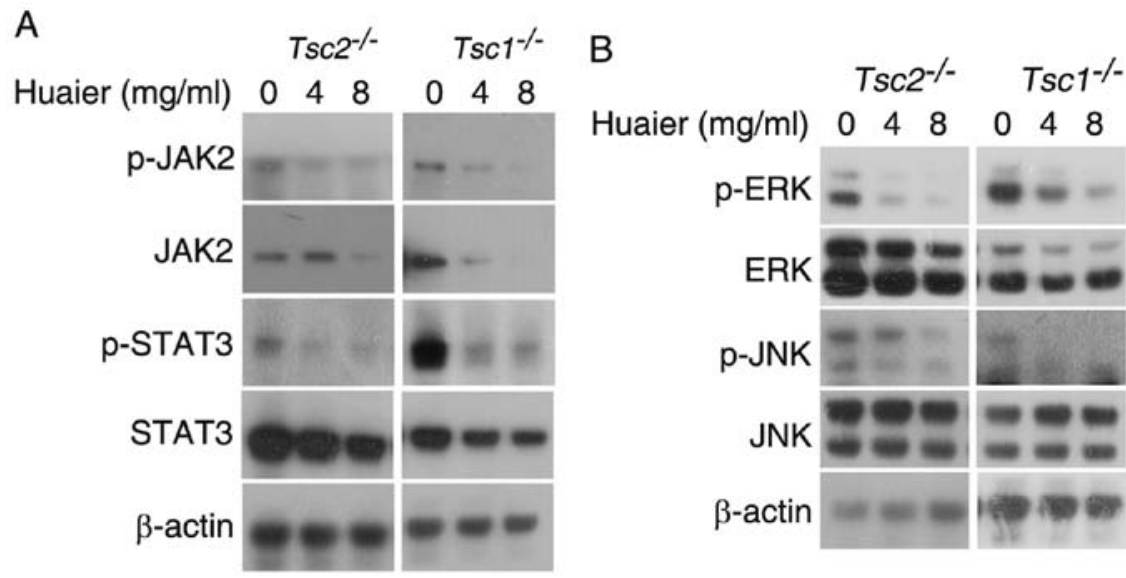

Figure 6. Huaier inhibits JAK2/signal transducer and activator of transcription 3 (STAT3) and mitogen-activated protein kinase (MAPK) signaling pathways in $T s c 1^{-\digamma}$ or $T s c 2^{-\digamma}$ MEFs. $T s c 2^{-/}$mouse embryonic fibroblasts (MEFs) and $T s c 1^{-\digamma}$ MEFs treated with Huaier aqueous extract at the concentrations of 0,4 and $8 \mathrm{mg} /$ $\mathrm{ml}$ for $48 \mathrm{~h}$ were subjected to immunoblotting for indicated proteins of (A) JAK2/STAT3 signaling pathway or (B) MAPK signaling pathway.

The scratch healing inhibition rates of $T s c 2^{-/}$MEFs and $T s \mathrm{Cl}^{-1}$ MEFs were $58.57 \pm 4.52$ and $82.01 \pm 13.97 \%$ after treatment with Huaier aqueous extract at a concentration of $4 \mathrm{mg} / \mathrm{ml}$ for $24 \mathrm{~h}$. Thus, Huaier significantly inhibits the migration of $T s c 1^{-1}$ or $T s c 2^{-/}$MEFs. Furthermore, we performed Transwell assay to assess the invasive capacity of $T s c 1^{-/-}$or $T s c 2^{-/}$MEFs in vitro. $T s c 2^{-\%}$ MEFs were treated with Huaier aqueous extract at the concentrations of 4 and $8 \mathrm{mg} / \mathrm{ml}$ for $12 \mathrm{~h}$. As observed in Fig. 5B, the number of $T s c 2^{--}$MEFs invading through the Matrigel-coated membrane was drastically decreased. In addition, the invasive capacity of $T s c 1^{-/-}$MEFs was also reduced by treatment with Huaier (Fig. 5B).

The epithelial-mesenchymal transition (EMT) is a critical process in cancer development, which enhances the metastatic capacity of cancer cells $(22,23)$. We therefore investigated the effects of Huaier on EMT of $T s c 1^{-/-}$or $T s c 2^{-1-}$ MEFs. We examined the expression levels of EMT markers by western blotting. As shown in Fig. 5C, Huaier treatment downregulated the protein levels of $\mathrm{N}$-cadherin, $\beta$-catenin, Slug, TCF8/ZEB1, Snail, and claudin-1 (24-26) in $T s c 1^{-/}$or $T s c 2^{-/-}$MEFs, indicating that Huaier inhibited EMT of $T_{s c l^{-1}}$ or $T s c 2^{-/}$MEFs. MMP-9 has been reported to be important in cancer metastasis $(27,28)$. Here we found that MMP-9 expression was reduced by Huaier treatment in a dose-dependent manner (Fig. 5C). Taken together, Huaier suppressed the metastatic ability of $T s c 1^{-/}$or $T s c 2^{-/}$MEFs in vitro.

Huaier inhibits JAK2/STAT3 and MAPK signaling pathways in $T s c 1^{-/}$or $T s c 2^{-/} M E F s$. JAK2/STAT3 pathway plays an important role in tumorigenesis and metastasis $(29,30)$. Inhibition of JAK2/STAT3 signaling pathway constrains cancer cell growth and induces apoptosis $(31,32)$. As shown in Fig. 6A, Huaier treatment downregulated the protein levels of JAK2, p-JAK2, STAT3, and p-STAT3 in $T s c 1^{-/}$or $T s c 2^{-/}$MEFs, suggesting that Huaier markedly inhibits JAK2/STAT3 signaling pathway in $T s c 1^{-/}$or $T s c 2^{-/}$MEFs. The MAPK pathway plays a crucial role in multiple cellular processes, such as cell proliferation, apoptosis, migration and invasion $(33,34)$. The MAPK superfamily consists of three mammalian MAP kinases, ERK, JNK, and p38 MAPK (35). As shown in Fig. 6B, we found that the phosphorylation of ERK and JNK was inhibited by
Huaier treatment in these two cell lines, indicating that Huaier restrains the MAPK signaling pathway in $T s c 1^{-/-}$or $T s c 2^{-1-}$ MEFs.

\section{Discussion}

Tumorigenesis is a multiple-step process involving aberrant genetic alterations. These complicated mechanisms may confer resistance to drugs which were used for targeted therapy of cancers. Therefore, it plays an important role in the treatment of cancers to target multiple pro-survival signaling pathways. Traditional Chinese medicine (TCM) has become an important source for developing new antitumor drugs based on some advantages including low toxicity, low cost, and the multi-targets (13). Huaier has been applied in TCM for approximately 1,600 years in China and has good clinical effects. As a single drug or adjuvant drug in the treatment of cancers, Huaier has attracted increasing attention in recent years.

The dysregulation of cell growth and cell death signals are main characteristics of tumors, so the strategy of inhibition of cell proliferation and induction of apoptosis could be exploited to treat tumors. $T s c 1^{-/}$MEFs and $T s c 2^{-/}$MEFs, two widely used TSC cell models (7,36-38), were applied in this study. We have demonstrated that Huaier could inhibit cell proliferation of $T s c 1^{-/} \mathrm{MEFs}$ and $T s c 2^{-/}$MEFs in vitro by CCK-8 assay, colony formation, and cell cycle analysis (Figs. 1 and 2). Moreover, we also showed that Huaier induced apoptosis in $T_{s c}{ }^{-\digamma}$ MEFs and $T_{s c} 2^{-\digamma}$ MEFs by flow cytometry and Hoechst staining (Fig. 3). These data provide potent in vitro evidence for treatment of TSC with Huaier.

Tumor metastasis is an extremely complicated multi-step process and play a critical role in tumorigenesis. Migration and invasion are two important cellular processes in tumor metastasis. In this study, we performed in vitro scratch assay and Transwell assay to evaluate the effects of Huaier on migratory and invasive ability in vitro of $T s c 1^{-/-} \mathrm{MEFs}$ and $T s 2^{-/}$MEFs. We showed that migration and invasion of $T s \mathrm{SC}^{-1-}$ or $T s c 2^{-/}$MEFs were markedly impaired by Huaier treatment in a dose-dependent manner (Fig. 5A and B). In addition, EMT is a process characterized with the conversion of epithelial cells into motile mesenchymal cells and the increase in 
cellular migration and invasion. EMT has been reported to occur in tumor metastasis $(23,33)$. Our study revealed that Huaier compromised the process of EMT in $\mathrm{Tscl}^{-/}$or $\mathrm{Tsc}^{-/}$ MEFs (Fig. 5C). As LAM is considered to be initiated by cells with mutations of TSC1 or TSC2, which metastasized from renal angiomyolipomas $(39,40)$, Huaier may be exploited as a potential drug targeting metastasis in the treatment of LAM and TSC.

JAK2/STAT3 signaling pathway has a critical role in cell proliferation, migration, apoptosis, and differentiation $(41,42)$. JAK2/STAT3 signaling pathway has been considered as a novel target for drugs against cancers $(43,44)$. STAT3 is an oncoprotein highly overexpressed in many cancers (45). STAT3 is required for aberrant proliferation and survival of TSC2-null cells (46). In addition, the role of MAPK signaling pathway in cell proliferation, apoptosis, motility, and morphogenesis has been extensively investigated (33). Suppression of MAPK signaling inhibited $T s c 2^{-/}$cell proliferation (47). In this study, we reported that Huaier inhibited JAK2/STAT3 signaling through downregulation of the total expression and phosphorylation of JAK2 and STAT3. Additionally, Huaier inhibited the phosphorylation/ activation of ERK and JNK in a dose-dependent manner in both $T s c 1^{-/-}$MEFs and Tsc2 $2^{-/-}$MEFs (Fig. 6). Collectively, we propose that Huaier inhibits the proliferation and metastasis of Tsc1- or Tsc2-null cells partially via downregulation of JAK2/STAT3 and MAPK signaling pathways.

In conclusion, we have clarified that the attenuation of JAK2/STAT3 and MAPK signaling are partially responsible for the inhibition of proliferation and metastasis of two TSC cell models induced by Huaier. Therefore, based on the low toxicity and multi-targets of Huaier treatment, Huaier may be a candidate drug for TSC treatment.

\section{Acknowledgements}

This study was financially supported by the National Natural Science Foundation of China (81403147) and grants from the Beijing University of Chinese Medicine (2014-JYBZZ-JS-024, 2015-JYB-XYQ-004).

\section{References}

1. Crino PB, Nathanson KL and Henske EP: The tuberous sclerosis complex. N Engl J Med 355: 1345-1356, 2006.

2. Weiner DM, Ewalt DH, Roach ES and Hensle TW: The tuberous sclerosis complex: A comprehensive review. J Am Coll Surg 187: 548-561, 1998.

3. Islam MP and Roach ES: Tuberous sclerosis complex. Handb Clin Neurol 132: 97-109, 2015.

4. Inoki K, Corradetti MN and Guan KL: Dysregulation of the TSC-mTOR pathway in human disease. Nat Genet 37: 19-24, 2005.

5. Curatolo $\mathrm{P}$ and Moavero R: mTOR Inhibitors in Tuberous Sclerosis Complex. Curr Neuropharmacol 10: 404-415, 2012

6. Orlova KA and Crino PB: The tuberous sclerosis complex. Ann N Y Acad Sci 1184: 87-105, 2010.

7. Zhang H, Cicchetti G, Onda H, Koon HB, Asrican K, Bajraszewski N, Vazquez F, Carpenter CL and Kwiatkowski DJ: Loss of Tsc1/Tsc2 activates mTOR and disrupts PI3K-Akt signaling through downregulation of PDGFR. J Clin Invest 112: 1223-1233, 2003.

8. Zhang H, Bajraszewski N, Wu E, Wang H, Moseman AP, Dabora SL, Griffin JD and Kwiatkowski DJ: PDGFRs are critical for PI3K/Akt activation and negatively regulated by mTOR. J Clin Invest 117: 730-738, 2007.
9. Carracedo A, Ma L, Teruya-Feldstein J, Rojo F, Salmena L, Alimonti A, Egia A, Sasaki AT, Thomas G, Kozma SC, et al: Inhibition of mTORC1 leads to MAPK pathway activation through a PI3K-dependent feedback loop in human cancer. J Clin Invest 118: 3065-3074, 2008.

10. Bissler JJ, McCormack FX, Young LR, Elwing JM, Chuck G, Leonard JM, Schmithorst VJ, Laor T, Brody AS, Bean J, et al: Sirolimus for angiomyolipoma in tuberous sclerosis complex or lymphangioleiomyomatosis. N Engl J Med 358: 140-151, 2008.

11. Franz DN, Leonard J, Tudor C, Chuck G, Care M, Sethuraman G, Dinopoulos A, Thomas G and Crone KR: Rapamycin causes regression of astrocytomas in tuberous sclerosis complex. Ann Neurol 59: 490-498, 2006.

12. Nie J, Zhao C, Deng LI, Chen J, Yu B, Wu X, Pang P and Chen X: Efficacy of traditional Chinese medicine in treating cancer. Biomed Rep 4: 3-14, 2016.

13. Liu J, Wang S, Zhang Y, Fan HT and Lin HS: Traditional Chinese medicine and cancer: History, present situation, and development. Thorac Cancer 6: 561-569, 2015.

14. Zhang N, Kong X, Yan S, Yuan C and Yang Q: Huaier aqueous extract inhibits proliferation of breast cancer cells by inducing apoptosis. Cancer Sci 101: 2375-2383, 2010.

15. Wang X, Zhang N, Huo Q and Yang Q: Anti-angiogenic and antitumor activities of Huaier aqueous extract. Oncol Rep 28: 1167-1175, 2012.

16. Wang X, Zhang N, Huo Q, Sun M, Lv S and Yang Q: Huaier aqueous extract suppresses human breast cancer cell proliferation through inhibition of estrogen receptor $\alpha$ signaling. Int $\mathrm{J}$ Oncol 43: 321-328, 2013.

17. Wu T, Chen W, Liu S, Lu H, Wang H, Kong D, Huang X, Kong Q, Ning Y and Lu Z: Huaier suppresses proliferation and induces apoptosis in human pulmonary cancer cells via upregulation of miR-26b-5p. FEBS Lett 588: 2107-2114, 2014.

18. Song X, Li Y, Zhang H and Yang Q: The anticancer effect of Huaier (Review). Oncol Rep 34: 12-21, 2015.

19. Kwiatkowski DJ, Zhang H, Bandura JL, Heiberger KM, Glogauer M, el-Hashemite N and Onda H: A mouse model of TSC1 reveals sex-dependent lethality from liver hemangiomas, and up-regulation of p70S6 kinase activity in Tsc1 null cells. Hum Mol Genet 11: 525-534, 2002.

20. Hu Z, Wang Y, Huang F, Chen R, Li C, Wang F, Goto J, Kwiatkowski DJ, Wdzieczak-Bakala J, Tu P, et al: Brain-expressed $\mathrm{X}$-linked 2 is pivotal for hyperactive mechanistic target of Rapamycin (mTOR)-mediated tumorigenesis. J Biol Chem 290: 25756-25765, 2015.

21. Bravo-Cordero JJ, Hodgson L and Condeelis J: Directed cell invasion and migration during metastasis. Curr Opin Cell Biol 24: 277-283, 2012.

22. Thiery JP, Acloque H, Huang RY and Nieto MA: Epithelial-mesenchymal transitions in development and disease. Cell 139: 871-890, 2009.

23. Tsai $\mathrm{JH}$ and Yang J: Epithelial-mesenchymal plasticity in carcinoma metastasis. Genes Dev 27: 2192-2206, 2013.

24. Zeisberg M and Neilson EG: Biomarkers for epithelial-mesenchymal transitions. J Clin Invest 119: 1429-1437, 2009.

25. Lee JM, Dedhar S, Kalluri R and Thompson EW: The epithelial-mesenchymal transition: New insights in signaling, development, and disease. J Cell Biol 172: 973-981, 2006.

26. Suh Y, Yoon CH, Kim RK, Lim EJ, Oh YS, Hwang SG, An S, Yoon G, Gye MC, Yi JM, et al: Claudin-1 induces epithelial-mesenchymal transition through activation of the c-Abl-ERK signaling pathway in human liver cells. Oncogene 32: 4873-4882, 2013

27. van Kempen LC and Coussens LM: MMP9 potentiates pulmonary metastasis formation. Cancer Cell 2: 251-252, 2002.

28. Merdad A, Karim S, Schulten HJ, Dallol A, Buhmeida A Al-Thubaity F, Gari MA, Chaudhary AG, Abuzenadah AM and Al-Qahtani MH: Expression of matrix metalloproteinases (MMPs) in primary human breast cancer: MMP-9 as a potential biomarker for cancer invasion and metastasis. Anticancer Res 34: 1355-1366, 2014.

29. Teng Y, Ross JL and Cowell JK: The involvement of JAK-STAT3 in cell motility, invasion, and metastasis. JAKSTAT 3: e28086, 2014.

30. Yu H, Lee H, Herrmann A, Buettner R and Jove R: Revisiting STAT3 signalling in cancer: New and unexpected biological functions. Nat Rev Cancer 14: 736-746, 2014

31. Du W, Hong J, Wang YC, Zhang YJ, Wang P, Su WY, Lin YW, Lu R, Zou WP, Xiong H, et al: Inhibition of JAK2/STAT3 signalling induces colorectal cancer cell apoptosis via mitochondrial pathway. J Cell Mol Med 16: 1878-1888, 2012. 
32. Judd LM, Menheniott TR, Ling H, Jackson CB, Howlett M, Kalantzis A, Priebe W and Giraud AS: Inhibition of the JAK2/STAT3 pathway reduces gastric cancer growth in vitro and in vivo. PLoS One 9: e95993, 2014.

33. Dhillon AS, Hagan S, Rath O and Kolch W: MAP kinase signalling pathways in cancer. Oncogene 26: 3279-3290, 2007.

34. Kim EK and Choi EJ: Pathological roles of MAPK signaling pathways in human diseases. Biochim Biophys Acta 1802: 396-405, 2010

35. Johnson GL and Lapadat R: Mitogen-activated protein kinase pathways mediated by ERK, JNK, and p38 protein kinases. Science 298: 1911-1912, 2002.

36. Uhlmann EJ, Apicelli AJ, Baldwin RL, Burke SP, Bajenaru ML, Onda H, Kwiatkowski D and Gutmann DH: Heterozygosity for the tuberous sclerosis complex (TSC) gene products results in increased astrocyte numbers and decreased p27-Kip1 expression in $T_{S C 2} 2^{+-}$cells. Oncogene 21: 4050-4059, 2002.

37. Ghosh S, Tergaonkar V, Rothlin CV, Correa RG, Bottero V, Bist P, Verma IM and Hunter T: Essential role of tuberous sclerosis genes TSC1 and TSC2 in NF-kappaB activation and cell survival. Cancer Cell 10: 215-226, 2006.

38. Zha X, Hu Z, Ji S, Jin F, Jiang K, Li C, Zhao P, Tu Z, Chen X, Di L, et al: $\mathrm{NF} \kappa \mathrm{B}$ up-regulation of glucose transporter 3 is essential for hyperactive mammalian target of rapamycin-induced aerobic glycolysis and tumor growth. Cancer Lett 359: 97-106, 2015.

39. Bittmann I, Rolf B, Amann G and Löhrs U: Recurrence of lymphangioleiomyomatosis after single lung transplantation: New insights into pathogenesis. Hum Pathol 34: 95-98, 2003.

40. Wang F, Chen X, Li C, Sun Q, Chen Y, Wang Y, Peng H, Liu Z, Chen $\mathrm{R}$, Liu $\mathrm{K}$, et al: Pivotal role of augmented $\alpha \mathrm{B}$-crystallin in tumor development induced by deficient TSC1/2 complex. Oncogene 33: 4352-4358, 2014.
41. O'Shea JJ, Gadina M and Schreiber RD: Cytokine signaling in 2002: New surprises in the Jak/Stat pathway. Cell 109 (Suppl): S121-S131, 2002

42. Kiu $\mathrm{H}$ and Nicholson SE: Biology and significance of the JAK/STAT signalling pathways. Growth Factors 30: 88-106, 2012.

43. Nam S, Xie J, Perkins A, Ma Y, Yang F, Wu J, Wang Y, Xu RZ, Huang W, Horne DA, et al: Novel synthetic derivatives of the natural product berbamine inhibit Jak2/Stat 3 signaling and induce apoptosis of human melanoma cells. Mol Oncol 6: 484-493, 2012

44. Um HJ, Min KJ, Kim DE and Kwon TK: Withaferin A inhibits JAK/STAT3 signaling and induces apoptosis of human renal carcinoma Caki cells. Biochem Biophys Res Commun 427: 24-29, 2012.

45. Johnston PA and Grandis JR: STAT3 signaling: Anticancer strategies and challenges. Mol Interv 11: 18-26, 2011.

46. Goncharova EA, Goncharov DA, Damera G, Tliba O, Amrani Y, Panettieri RA Jr and Krymskaya VP: Signal transducer and activator of transcription 3 is required for abnormal proliferation and survival of TSC2-deficient cells: Relevance to pulmonary lymphangioleiomyomatosis. Mol Pharmacol 76: 766-777, 2009.

47. Mi R, Ma J, Zhang D, Li L and Zhang H: Efficacy of combined inhibition of mTOR and ERK/MAPK pathways in treating a tuberous sclerosis complex cell model. J Genet Genomics 36: 355-361, 2009. 